Originalien

Somnologie $2020 \cdot 24: 151-158$

https://doi.org/10.1007/s11818-020-00259-4

Published online: 12 August 2020

(c) The Author(s) 2020
H. Woehrle ${ }^{1} \cdot$ C. Schoebel ${ }^{2} \cdot$ O. Oldenburg ${ }^{3} \cdot$ P. Young ${ }^{4} \cdot$ I. Fietze ${ }^{5} \cdot$ J. H. Ficker ${ }^{6,7}$. C. Bischoff-Everding ${ }^{8} \cdot$ B. Libutzki ${ }^{8,9} \cdot$ M. Arzt ${ }^{10}$

'Sleep and Ventilation Center Blaubeuren, Respiratory Center Ulm, Ulm, Germany

${ }^{2}$ Department of Pneumology, Ruhrlandklinik, West German Lung Center, University Hospital Essen, University Duisburg-Essen, Essen, Germany

${ }^{3}$ Ludgerus-Kliniken Münster, Clemenshospital, Münster, Germany

${ }^{4}$ Neurology, Medical Park Klinik Reithofpark, Bad Feilnbach, Germany

${ }^{5}$ Interdisziplinares Schlafmedizinisches Zentrum, CC12, Charite-Universitatsmedizin Berlin, Berlin, Germany

${ }^{6}$ Department of Respiratory Medicine, Allergology and Sleep Medicine, General Hospital Nuremberg, Nuremberg, Germany

${ }^{7}$ Paracelsus Medical University, Nuremberg, Germany

${ }^{8} \mathrm{HGC}$ Healthcare Consultants GmbH, Düsseldorf, Germany

${ }^{9}$ Department of Psychiatry, Interdisciplinary Center Psychopathology and Emotion regulation (ICPE), University of Groningen, University Medical Center Groningen, Groningen, The Netherlands

${ }^{10}$ Department of Internal Medicine II, Cardiology and Pneumology, Universitätsklinikum Regensburg, Regensburg, Germany

\title{
Low long-term mortality in patients with sleep apnoea and positive airway pressure therapy: analysis of a large German healthcare database
}

\section{Introduction}

Sleep apnoea (SA) is a highly prevalent condition and its prevalence is dependent mostly on age, sex and weight [1, 2]. There are two types of SA: obstructive sleep apnoea (OSA) and central sleep apnoea (CSA). OSA is the most common form of SA and occurs as a result of partial or complete upper airway collapse [3], which impedes respiratory flow and results in unintentional pauses in breathing during sleep with associated hypoxemia. CSA is characterised by a cessation or decrease of ventilatory effort during sleep [4]. Generally, patients with SA have poor sleep quality and often experience excessive daytime sleepiness. In addition, they are at risk of experiencing a variety of pathophysiologic health conditions, including cardiovascular disease [5-7], cognitive impairment, psychiatric problems, cardiovascular disease and di- abetes $[8,9]$, and have a reduced capacity to perform activities of daily living [10, 11].

First-line treatment for SA is positive airway pressure (PAP) therapy, which prevents airway collapse during sleep. It is widely accepted that PAP therapy provides effective treatment of SA $[12,13]$ and improves symptoms [14-17]. Observational data indicate that PAP therapy may have the potential to deliver a beneficial impact on morbidity and mortality [7, 18-20]. However, up to now there are no data from large randomised trials which could unequivocally demonstrate positive effects on survival, particularly in OSA patients with comorbidities [21]. However, achieving adequate compliance with PAP therapy in these studies was difficult, and the mean usage was below a threshold considered necessary to make PAP therapy effective [21]. Therefore, there remains a need for longer- term data obtained in larger groups of representative patients managed during routine clinical practice to facilitate better understanding of these issues and to identify subgroups of patients who might derive the greatest benefit from treatment.

Although advances in sleep medicine over recent years and the availability of improved diagnostic tools have improved the recognition and treatment of SA, under-diagnosis and under-treatment are still important issues [22]. Continuous positive airway pressure (CPAP) is consistently recommended as the first-choice treatment for patients with moderate to severe OSA [12, 23], but information on long-term hard clinical outcomes is limited.

This study used representative data from a large German health claims database to identify patients with a confirmed diagnosis of SA. Propensity score 


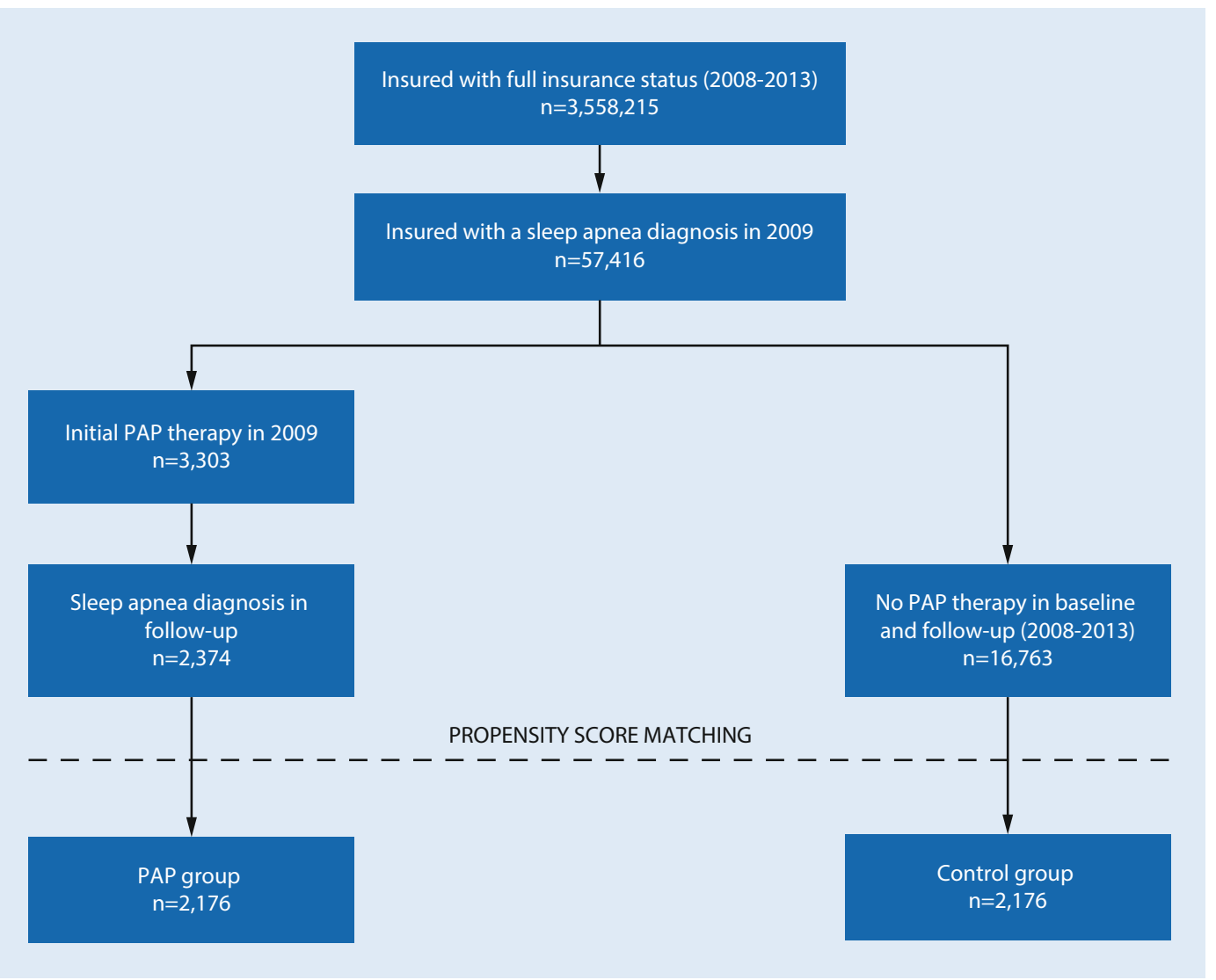

Fig. $1<$ Study flow diagram. PAP positive airway pressure matching was used to generate two patient groups and to minimize selection bias: SA with PAP treatment (PAP group) and SA without PAP treatment (control group). Long-term hospitalisation data and total mortality rates were compared in the two patient groups.

\section{Methods}

\section{Data source}

This study was an exploratory, retrospective, longitudinal, two-cohort study using German health claims data from the Health Risk Institute (HRI) research database for the years 2008 through 2013. Routine health claims data with at least 4.4 million covered lives were made available, consisting of anonymized and pseudonymized datasets from over 80 statutory health insurance (SHI) companies throughout Germany. Data were adjusted to Germany's typical age and sex distribution based on Federal Statistical Office figures, thus ensuring that the study population provided an approximately $5 \%$ (4.4 of 82 mil- lion) representative random sample of the German population [24]. All data were retrieved from actual trans-sectorial healthcare services and prescription practices in Germany and are predominantly free of selection biases. The data are used by SHIs for administrative purposes, reflecting allocation modes of several healthcare services including German International Classification of Procedures in Medicine (ICPM) codes and medical aids for procedures, German Diagnosis Related Groups (G-DRG) codes for billing purposes and International Statistical Classification of Diseases and Related Health Problems 10th revision German Modification (ICD10-GM) codes for classifying diseases. The overall study design was predefined by a detailed analysis protocol following the Strengthening the Reporting of Observational Studies in Epidemiology (STROBE) initiative criteria [25]. The analysis did not involve any decisions regarding interventions or the omission of interventions. Accordingly, institutional review board/ethical approval and informed consent of the individual were not required. Moreover, all individual patient data are de-identified in the research database to comply with German data protection regulations.

\section{Study population}

The primary study population comprised all persons who were continuously insured by SHIs and had complete medical records within the study period (01 January 2008 until 31 December 2013) or died within the follow-up period. Selected study patients must have had at least one diagnosis referring to SA in the index year (2009; ICD-10-GM code G47.30/31/38/39 [sleep apnea]; diagnosis from inpatient and/or outpatient sector) and at least one diagnosis of SA during follow-up. In total, 57,416 cases of SA were identified within the database in 2009 (• Fig. 1). Importantly, it was not differentiated whether selected patients were incident or prevalent cases. In our opinion, deciding for a mixed prevalent and incident user cohort provided a better indication of the efficacy of treatments in real clinical practice. 
Somnologie 2020 $24: 151-158$ https://doi.org/10.1007/s11818-020-00259-4

(c) The Author(s) 2020

H. Woehrle · C. Schoebel · O. Oldenburg · P. Young · I. Fietze · J. H. Ficker · C. Bischoff-Everding · B. Libutzki $\cdot$ M. Arzt

Low long-term mortality in patients with sleep apnoea and positive airway pressure therapy: analysis of a large German healthcare database

\section{Abstract}

Background. There are limited data on longterm mortality in sleep apnoea (SA) patients with and without positive airway pressure (PAP) therapy. This retrospective cohort study investigated long-term hospitalisation and mortality rates in SA patients from a German statutory health insurance (SHI) database who did versus did not receive PAP therapy.

Methods. Patients had continuous insurance coverage from 01 January 2008 to 31 December 2013, complete medical records and $\geq 1$ SA-related diagnosis in 2009. Those receiving PAP were matched with a control group not treated with PAP. Outcomes (hospitalisations including stays in the sleep laboratory) were compared between groups the year prior to and the 4 years after SA diagnosis. Mortality was assessed in the 4 years after SA diagnosis.

Results. 2176 PAP therapy recipients were matched with 2176 controls. The PAP group had a higher rate of hospitalisation in the year before SA diagnosis than the control group (80.2\% vs. $26.6 \% ; p=0.0016)$. After diagnosis, the PAP group had a higher hospitalisation rate only in year $1(p<0.05)$, and average length of stay per hospitalisation was lower in the PAP group ( $p<0.05$ vs. control at years 1 , 2 and 4). Cumulative all-cause mortality after year $3(3.4 \%$ vs. $4.6 \% ; p=0.0287)$ and after year 4 (4.8\% vs. $6.5 \% ; p=0.0175)$ was significantly lower in SA patients receiving PAP versus controls (relative risk reduction for death after 4 years: $25.5 \%$ ).

Conclusion. This real-world cohort study showed an association between long-term PAP therapy use and lower mortality, a higher rate of hospitalisations before and shorter hospital stays after treatment initiation.

Keywords

Sleep-disordered breathing - Treatment . Hospitalisation · Prognosis

\section{Geringe Langzeitmortalität bei Patienten mit Schlafapnoe und positiver Atemwegsdrucktherapie: Analyse einer großen deutschen Gesundheitsdatenbank}

\section{Zusammenfassung}

Hintergrund. Es liegen nur begrenzte Daten zur Langzeitmortalität bei Patienten mit Schlafapnoe (SA) mit und ohne positiver Atemwegsdrucktherapie (PAP) vor. Diese retrospektive Kohortenstudie untersuchte Langzeit-Krankenhausaufenthalte und Mortalitätsraten bei SA-Patienten aus einer Datenbank der gesetzlichen Krankenversicherungen (SHI), die eine bzw. keine PAPTherapie erhielten.

Methoden. Eingeschlossen wurden Patienten mit kontinuierlichem Versicherungsschutz zwischen 1. Januar 2008 und 31. Dezember 2013, vollständigen Krankenakten im Jahr 2009 und $\geq 1$ SA-bezogenen Diagnose. Patienten, die eine PAP-Therapie erhielten, wurden mit einer Kontrollgruppe verglichen, die nicht mit PAP behandelt wurde. Krankenhausaufenthalte (inklusive Aufenthalte im Schlaflabor) wurden zwischen den Gruppen im Jahr vor und innerhalb der ersten 4 Jahre nach SA-Diagnose verglichen. Die Mortalität wurde innerhalb der 4 Jahre nach Diagnosestellung erfasst.

Ergebnisse. Insgesamt 2176 Patienten mit PAP-Therapie wurden 2176 Kontrollpatienten ohne PAP-Therapie mit ähnlichen Charakteristika zugeordnet. Die Gruppe mit PAPTherapie wies im Vergleich zur Kontrollgruppe im Jahr vor der SA-Diagnose eine höhere Krankenhausaufenthaltsrate auf $(80,2 \%$ vs. $26,6 \% ; p=0,0016)$. Nach der SA-Diagnose hatte die PAP-Gruppe nur im Jahr 1 eine höhere Krankenhausaufenthaltsrate $(p<0,05)$, und die durchschnittliche Verweildauer pro Krankenhausaufenthalt war in der PAP-Gruppe kürzer ( $p<0,05$ vs. Kontrolle in den Jahren 1 , 2 und 4). Die kumulative Gesamtmortalität nach Jahr $3(3,4 \%$ vs. $4,6 \% ; p=0,0287)$ und Jahr $4(4,8 \%$ vs. $6,5 \% ; p=0,0175)$ war bei SA-Patienten, die PAP erhielten, signifikant niedriger als bei den Kontrollpersonen. Es zeigte sich eine $25,5 \%$ ige Verringerung des Sterberisikos nach 4 Jahren.

Schlussfolgerung. Diese Kohortenstudie zeigte einen Zusammenhang zwischen der Langzeit-PAP-Therapie und geringerer Mortalität, höherer Krankhausaufenthaltsrate vor und kürzeren Krankenhausaufenthalten nach Therapiebeginn.

\section{Schlüsselwörter}

Schlafbezogene Atmungsstörungen . Behandlung · Krankenhausaufenthalt . Prognose
All patients with a relevant diagnosis code of SA who were treated with PAP therapy in 2009 (medical aids list $14.24 .20 / 21 / 22 / 23 / 24 / 25$ ) initiated for the first time in 2009 were eligible for inclusion in the PAP group. PAP therapy could include continuous positive airway pressure (CPAP), auto-CPAP, bilevel CPAP (BPAP) or any other device for the treatment of sleep-related breathing disorders. There was no differentiation between CPAP and BPAP. All patients with SA who did not receive PAP therapy in baseline and follow-up (2008-2013) were allocated to the control group (• Fig. 1).

\section{Data collection}

Anonymous data (including patient demographics, comorbid conditions, hospitalisations and deaths) were extracted from the SHI database by a single investigator. Baseline data for matching were from 2008, the index year was 2009 and the 4-year follow-up covered the period 2009 to 2013.

\section{Hospitalisations}

The number of hospitalisations and the total duration of each hospitalisation were retrieved from the HRI database. In Germany, more than $90 \%$ of all sleep laboratories were associated with a hospital at that time (very few are run in the 
Table 1 Patient characteristics of matched groups at baseline

\begin{tabular}{|c|c|c|}
\hline & $\begin{array}{l}\text { Control group } \\
(n=2176)\end{array}$ & $\begin{array}{l}\text { PAP group } \\
(n=2176)\end{array}$ \\
\hline Male, $n(\%)$ & $1723(79.2)$ & $1723(79.2)$ \\
\hline \multicolumn{3}{|l|}{ Age, years } \\
\hline Males & $58.52 \pm 11.39$ & $58.54 \pm 11.4$ \\
\hline Females & $63.28 \pm 10.26$ & $63.34 \pm 10.27$ \\
\hline \multicolumn{3}{|c|}{ Age range, $n$ (\%) } \\
\hline $0-39$ years & $98(4.5)$ & $98(4.5)$ \\
\hline 40-59 years & $959(44.1)$ & $958(44.0)$ \\
\hline 60-69 years & $661(30.4)$ & $655(30.1)$ \\
\hline 70-79 years & $420(19.3)$ & 428 (19.7) \\
\hline$\geq 80$ years & $38(1.7)$ & $37(1.7)$ \\
\hline
\end{tabular}

outpatient sector) [26]. As a result, there was a high number of admissions to hospital sleep clinics for polysomnography (PSG) during PAP therapy initiation and follow-up (at 3 and 6 months as a minimum).

\section{Mortality}

All-cause mortality (total mortality) was determined based on deaths recorded in the SHI database.

\section{Statistical analysis}

An analytical file comprising all patients and variables required for planned analyses was created from information contained exclusively within the source material (i.e. the full HRI research database). The analytical file was at the person level and included data on demographics and clinical characteristics as described above. Variables were created based on information provided by medical and pharmacy claims that were linked at the person level.

\section{Propensity score matching}

The comparability of the studygroups was ensured using a pre-adjusted, representative database and by applying propensity score matching (PSM) when creating the PAP therapy group and control groups. This helped to minimize the risk of selection biases or confounders. Of the total SA population in the index year 2009, cases for the control group were identified using PSM according to the method described by Rosenbaum and Rubin [27]. When deciding for the nearest neighbour matching on a 1:1 basis without replacement, it was necessary to select parameters for the preparation of comparable profiles of SA cases. These parameters were age and sex, inpatient and outpatient diagnosis codes (three digits) and Anatomical Therapeutic Chemical (ATC) classification system groups (four digits), annual average cost categories for hospitalisation, outpatient, drugs, remedies and sick pay, as well as number of days off work and whether the SA patient was defined as an incident or prevalent case. Data required for matching of the PAP therapy and control groups were collected for the year prior to treatment. Multivariable logistic regression was used to estimate a propensity score for each subject. Identifying the most similar cases or rather the nearest neighbours of cases included in the PAP group was the basis for building the control group. The quality of PSM was assessed using the percent reduction in bias (PBR) [28]. A PBR score of $85.3 \%$ indicated that the PSM algorithm used resulted in good harmonisation of propensity score distribution in the PAP and control groups. To guarantee exclusion of all putative outliers, the $99 \%$ percentile approach was applied. The aim was to ensure that the difference between the variance-normalised averages remained below a calliper of $10 \%$.
Data are presented as mean values \pm standard deviation (SD) and/or 95\% confidence intervals (CI). Chisquare tests were used to compare nominally distributed data. Kaplan-Meier survival analysis using the Tarone-Ware test was used to determine significant differences in mortality between the PAP and control groups. A two-sided $p$-value of $<0.05$ was considered to be statistically significant. The central statistical software program used to evaluate data was SAS Enterprise Guide 4.3 (SAS Institute Inc., Cary, NC, USA).

\section{Results}

The total population with continuous insurance from January 2008 to December 2013 included 3,558,215 patients, all of whom were eligible for inclusion. The insurance database recorded 3303 patients as having started PAP therapy in 2009, 2374 of whom had a diagnosis of SA in follow-up. A total of 16,763 patients had an SA diagnosis but did not receive PAP therapy. PSM was used in these patients to form a control group of equal size to the PAP group $(n=2176)$ (• Fig. 1). After the matching process, patient demographic data and baseline characteristics were similar in the PAP therapy and control groups (• Table 1).

\section{Hospitalisation}

In the year prior to SA diagnosis, the proportion of patients hospitalised in the PAP group was significantly higher than that in the matched control group $(80.2 \%$ vs $26.6 \%$; $p=0.0016)$. In the first year of follow-up, the number of patients hospitalised was higher in the PAP therapy versus control group, reflecting the occurrence of PSG testing-related hospitalisations (•Table 2). Over years 2, 3 and 4 of follow-up, the number of patients hospitalised and the number of admissions per hospitalised patient were similar in the PAP therapy and control groups (- Table 2 ). In contrast, the average length of stay per hospitalisation was consistently lower in the PAP therapy versus control group; between-group differences achieved statistical significance in years 1, 2 and 4 (• Table 2). 


\begin{tabular}{|c|c|c|}
\hline & Control group $(n=2176)$ & PAP group $(n=2176)$ \\
\hline \multicolumn{3}{|c|}{ Patients hospitalised, $\%$} \\
\hline Year 1 & 28.0 & $34.5^{\mathrm{a}}$ \\
\hline Year 2 & 27.5 & 29.3 \\
\hline Year 3 & 27.9 & 29.9 \\
\hline Year 4 & 29.0 & 29.0 \\
\hline \multicolumn{3}{|c|}{ Admissions per hospitalised patient, $n$} \\
\hline Year 1 & 1.67 & 1.60 \\
\hline Year 2 & 1.65 & 1.64 \\
\hline Year 3 & 1.74 & 1.73 \\
\hline Year 4 & 1.67 & 1.72 \\
\hline \multicolumn{3}{|c|}{ Average length of stay per hospitalisation, days } \\
\hline Year 1 & 8.02 & $7.25^{\mathrm{a}}$ \\
\hline Year 2 & 9.04 & $8.15^{\mathrm{a}}$ \\
\hline Year 3 & 9.08 & 8.83 \\
\hline Year 4 & 9.26 & $7.93^{\mathrm{a}}$ \\
\hline \multicolumn{3}{|c|}{$\begin{array}{l}\text { All hospitalisations regardless of whether they were related to diagnosis and treatment of sleer } \\
\text { apnoea or not } \\
\text { PAP positive airway pressure } \\
{ }^{a}<<0.05 \text { vs control group }\end{array}$} \\
\hline
\end{tabular}

Table 3 All-cause mortality in sleep apnoea patients by year of follow-up

\begin{tabular}{llll}
\hline Mortality, $\boldsymbol{n}(\%)$ & Control group $(\boldsymbol{n}=\mathbf{2 1 7 6})$ & PAP group $(\boldsymbol{n}=\mathbf{2 1 7 6})$ & $\boldsymbol{p}$-value \\
\hline Year 1 & $27(1.24)$ & $16(0.74)$ & 0.0914 \\
Year 2 & $66(3.03)$ & $48(2.21)$ & 0.0852 \\
Year 3 & $100(4.60)$ & $73(3.35)$ & $0.0287^{*}$ \\
Year 4 & $141(6.48)$ & $105(4.83)$ & $0.0175^{*}$ \\
\hline $\begin{array}{l}\text { PAP positive airway pressure } \\
\text { *Statistically significant } \boldsymbol{p} \text {-value }\end{array}$ & & \\
\hline
\end{tabular}

\section{Mortality}

There were no statistically significant differences between the PAP and control groups in all-cause mortality in the first 2 years of follow-up (• Table 3 ). In years 3 and 4 of follow-up, all-cause mortality was significantly lower in patients who used PAP therapy compared to controls (- Table 3). Survival curves in the PAP therapy and control groups are shown in - Fig. 2. At 4 years, the risk of death was $25 \%$ lower in PAP therapy users compared to controls $(p=0.0175)$.

\section{Discussion}

The results of this study based on a large German insurance database population showed a decrease in mortality and the duration of hospitalisations over 4 years' follow-up in SA patients treated with
SA-related mortality over 2 years of follow-up than similar patients who did not use PAP therapy [29]. Patients in the US study were not matched with controls and the number of patients in each group was vastly different, with the majority receiving PAP therapy. In addition, there was a significant difference between the PAP and control groups at baseline with respect to comorbidities; PAP recipients had an overall higher burden of disease and the most common comorbidities were hypertension, dyslipidaemia and type 2 diabetes. Similar benefits of PAP therapy with respect to mortality were also observed in a 2-year Danish registry, which matched patients with a control group based on age, sex and socioeconomic variables, but only after adjustment for multiple comorbidities [30]. A population-level analysis from Spain indicated that treatment with CPAP was associated with reductions in mortality on multivariate analysis at a population level [31]. However, this was entirely attributable to reduced mortality in men using CPAP, whereas use of CPAP was associated with increased mortality in women [31]. Similar findings were obtained in an analysis of a Danish historical cohort, which showed lower mortality rates in middle-aged and elderly males treated with CPAP, again after adjustment for multiple comorbidities, but not in females [32]. Data from both the Spanish and Danish groups highlight significant interactions between the effect of CPAP on mortality and several comorbid conditions, including cerebrovascular disease, hypertension and diabetes mellitus, and suggest that gender may also influence outcomes during CPAP therapy [31, 32]. The influence of both gender and comorbidities on CPAP therapy and its effect on mortality are important areas for future research. The inclusion of more females in clinical trials could assist with this given that males have tended to predominate in CPAP study populations (74\% in the Spanish study, $75 \%$ in the Danish cohort and 79\% in this analysis).

The Sleep Apnea Cardiovascular Endpoints (SAVE) study (NCT00738179) was the first large randomised controlled trial to investigate the effects of CPAP therapy on morbidity and mor- 


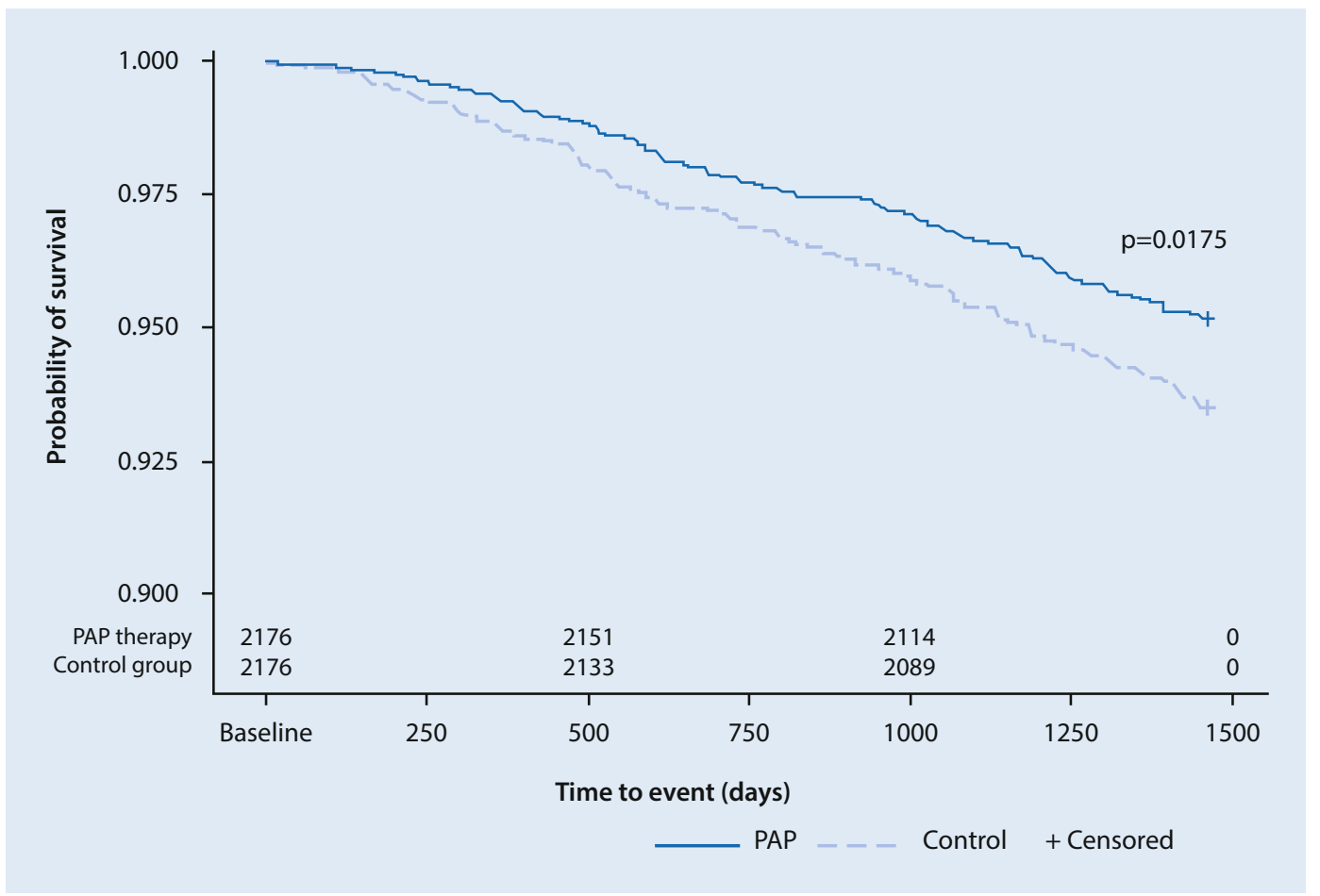

Fig. $2<$ All-cause mortality in patients receiving positive airway pressure therapy (PAP) versus controls tality in patients with sleep apnoea at risk for cardiovascular events [21]. It enrolled non-sleepy patients with mild to moderate OSA who were randomised to treatment with CPAP or usual care. In contrast to our study findings, use of CPAP did not reduce hospitalisations or mortality. Although the patient populations in the two studies appeared relatively similar (in terms of patient sex, mean age, rates of hypertension and diabetes, and duration of followup), PAP therapy in the SAVE trial consisted of CPAP only and patients had an obstructive form of sleep apnoea. In contrast, a variety of PAP devices were used in our study, as chosen by individual physicians as most appropriate for each patient. The database could not provide specific information on the type of sleep apnoea each patient had, but the variety of devices chosen suggests that the vast majority of patients had obstructive sleep apnoea and a minority had central sleep apnoea. Another important factor is compliance with therapy, which was low (mean $3.3 \mathrm{~h} /$ night) in the SAVE study and unknown in our analysis. However, CPAP device data from Germany suggest that adherence rates and device usage are good $(91.8 \%$ of patients with device use of $>4 \mathrm{~h} /$ night and average usage of $>6 \mathrm{~h} /$ night) [33].

It has been suggested that CPAP use for $4 \mathrm{~h} /$ night or more is required to obtain many of the cardiovascular benefits that have been reported to be associated with CPAP therapy [34-38]. Additional information on the effects of PAP therapy will come from the Effect of Adaptive Servo-Ventilation on Survival and Hospital Admissions in Heart Failure (ADVENT-HF; NCT01128816) randomised trial [39]. These, and other data, are clearly needed to provide more definitive information on the effects of PAP therapy on morbidity and mortality in patients with cardiovascular disease. It is likely that standardized definitions for different patient phenotypes will be needed, each of which will have different therapy requirements and responses.

The inclusion of a large representative population of SA patients in this study is one of its strengths, improving generalisability of the study results. In contrast to long-term randomised outcome trials, SA patients with severe SA-related symptoms are included in the present analysis. However, the study also has a number of limitations. Firstly, in contrast to a randomised controlled trial, by design, the present study cannot prove a causal relationship between PAP therapy and outcomes, since the decision for or against PAP therapy by the patient and the physician may confer selection bias. The dataset is based on SHI claims data, privately insured persons are not included in the dataset. However, only $10 \%$ of the German population are privately insured and representativeness of the database to the German population has been proven [24]. Similarly, persons who do not consult a physician are not visible in the dataset. This bias is deemed low, as SA heavily impacts quality of life, thus motivating patients to seek professional help. Moreover, the SHI database used includes basic records applicable to insurance needs; there is no detailed clinical patient information. As a result, it was not possible to differentiate between the two main forms of SA (OSA vs. CSA), determine the indication for PAP therapy or know why PAP therapy was not used in control patients. PSM was used to minimise differences between the groups and there were no relevant differences in demographics, morbidity, disease severity or costs between groups at baseline, but selection bias cannot be completely excluded, particularly for factors relating to variables that were not available from the insurance database and there- 
fore could not be included in the matching process. Another factor that could have affected our findings are unknown differences between the PAP therapy and control groups. A small proportion of the control group may have used alternative treatments for SA such as mandibular advancement devices. Unknown effective therapy of SA in the control group would confer a conservative bias to the presented results favouring no differences in outcomes between the PAP and the control groups. Because we were unable to determine the reasons why PAP therapy was or was not used from the insurance database, it is possible that patients using PAP differed from the control group in other ways, such as health-seeking behaviours, motivation and partner/family support. The analysis relies on the quality of coding by physicians and healthcare professionals, a factor which cannot be assessed within SHI claims data analyses. In addition, the dataset's primary purpose is SHI billing and "upcoding" of diagnoses to trigger higher allocation cannot be eliminated. It may be possible that patients diagnosed with SA who did not receive PAP only showed minor symptoms at diagnosis. Since we do not have any data on the severity of SA at the time of diagnosis, one might speculate that among the patients who were treated with PAP, there might have been more individuals with severe SA than in the group of patients where the treating physicians decided not initiate PAP treatment. Nevertheless, despite this possible imbalance we were able to demonstrate lower mortality in patients with PAP therapy. Therefore, one might speculate that the real effect of PAP therapy on mortality might be even stronger than the effect we were able to demonstrate. Adherence to PAP therapy is an important aspect of ensuring that treatment benefits are achieved [14, 15] and is another factor that could have influenced the findings of this study because the SHI database provided no information on compliance. Previous data suggest good compliance rates in the German setting ( $92 \%$ when defined as device use for $>4 \mathrm{~h} /$ night) [33]. Nevertheless, it seems reasonable to assume that increasing adherence rates to closer to $100 \%$ could contribute to even

greater reductions in morbidity and mortality in SA patients treated with PAP than were documented in this study.

\section{Conclusion}

This real-world cohort study showed an association between long-term PAP therapy use and lower mortality, higher rate of hospitalisations before and shorter hospital stays after treatment initiation. This analysis should stimulate future outcome research with smart trial designs in representative patient populations that allow definitive conclusions.

\section{Corresponding address

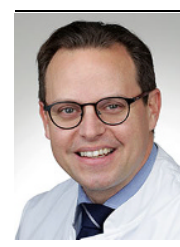 \\ Prof. Dr. M. Arzt \\ Department of Internal Medicine II, Cardiology and Pneumology, Universitätsklinikum Regensburg Franz-Josef-Strauß-Allee 11, 93053 Regensburg, Germany michael.arzt@ukr.de}

Acknowledgements. Medical writing assistance was provided by Nicola Ryan, independent medical writer, funded by ResMed Germany Inc.

Funding. This analysis by HGC Healthcare Consultants $\mathrm{GmbH}$ was funded by ResMed Germany Inc.

Funding. Open Access funding provided by Projekt DEAL.

\section{Compliance with ethical guidelines}

Conflict of interest. H. Woehrle is a paid consultant to ResMed and has received research grants. C. Schoebel reports personal fees from ResMed. O. Oldenburg reports grants and personal fees from ResMed and Sorin/Respircardia. P. Young reports personal fees from Sanofi Genzyme, Biomarin, UCB Pharma, Medice, ResMed, Loewenstein Medical and Vanda, and grants from Lowensteinstiftung and the German Ministry of Education and Science (BMBF), outside the submitted work. I. Fietze reports grants from ResMed, Philips, Fisher \& Paykel, Hoffrichter, Löwenstein Medical and Weinmann, and personal fees from ResMed, outside the submitted work. J.H. Ficker reports personal fees and non-financial support from ResMed and Weinmann, outside the submitted work. C. BischoffEverding is $\mathrm{CEO}$ of HGC. B. Libutzki is employed at HGC, a German healthcare consulting firm that received honoraria from ResMed for health economic outcome research. M. Arzt reports personal fees from Boehringer Ingelheim, Jazz Pharmaceuticals, Inspire and NRI; grants and personal fees from ResMed and Philips Respironics as well as grants from the Else
Kröner-Fresenius-Stiftung and the ResMed Foundation outside the submitted work.

For this article no studies with human participants or animals were performed by any of the authors. All studies performed were in accordance with the ethical standards indicated in each case.

Open Access This article is licensed under a Creative Commons Attribution 4.0 International License, which permits use, sharing, adaptation, distribution and reproduction in any medium or format, as long as you give appropriate credit to the original author(s) and the source, provide a link to the Creative Commons licence, and indicate if changes were made. The images or other third party material in this article are included in the article's Creative Commons licence, unless indicated otherwise in a credit line to the material. If material is not included in the article's Creative Commons licence and your intended use is not permitted by statutory regulation or exceeds the permitted use, you will need to obtain permission directly from the copyright holder. To view a copy of this licence, visit http://creativecommons.org/licenses/by/4.0/.

\section{References}

1. Park JG, Ramar K, Olson EJ (2011) Updates on definition, consequences, and management of obstructive sleep apnea. Mayo Clin Proc 86:549-554 (quiz 554-545)

2. Young T, Skatrud J, Peppard PE (2004) Risk factors for obstructive sleep apnea in adults. JAMA 291:2013-2016

3. Punjabi NM (2008) The epidemiology of adult obstructive sleep apnea. Proc Am Thorac Soc 5:136-143

4. American Academy of Sleep Medicine (2001) The international classification of sleep disorders, revised: diagnostic and coding manual. American Academy of Sleep Medicine, Chicago

5. Oldenburg O, Bitter T, Fox H, Horstkotte D (2014) Sleep-related breathing disorders and (resulting) cardiovascular diseases. Herz 39:37-44

6. Peker Y, Carlson J, Hedner J (2006) Increased incidence of coronary artery disease in sleep apnoea: a long-term follow-up. Eur Respir J 28:596-602

7. Ge X, Han F, Huang Y, Zhang Y, Yang T, Bai C, Guo X (2013) Is obstructive sleep apnea associated with cardiovascular and all-cause mortality? PLoS One 8:e69432

8. Aurora RN, Punjabi NM (2013) Obstructive sleep apnoea and type 2 diabetes mellitus: a bidirectional association. Lancet Respir Med 1:329-338

9. Zamarron C, Garcia Paz V, Morete E, del Campo Matias F (2008) Association of chronic obstructive pulmonary disease and obstructive sleep apnea consequences. Int J Chron Obstruct Pulmon Dis 3:671-682

10. National Heart Lung and Blood Institute (2012) What is sleep apnea? http://www.nhlbi.nih. gov/health/health-topics/topics/sleepapnea/. Accessed 25 June 2014 (vol 2014)

11. Rakel RE (2009) Clinical and societal consequences of obstructive sleep apnea and excessive daytime sleepiness. Postgrad Med 121:86-95

12. Epstein LJ, Kristo D, Strollo PJ Jr., Friedman N, Malhotra A, Patil SP, Ramar K, Rogers R, Schwab RJ, WeaverEM, Weinstein MD (2009) Clinical guideline for the evaluation, management and long-term 
care of obstructive sleep apnea in adults. J Clin Sleep Med 5:263-276

13. Gay P, Weaver T, Loube D, Iber C (2006) Evaluation of positive airway pressure treatment for sleep related breathing disorders in adults. Sleep 29:381-401

14. Weaver TE, Grunstein RR (2008) Adherence to continuous positive airway pressure therapy: the challenge to effective treatment. Proc Am Thorac Soc 5:173-178

15. Weaver TE, Maislin G, Dinges DF, Bloxham T, George CF, Greenberg H, Kader G, Mahowald M, Younger J, Pack Al (2007) Relationship between hours of CPAP use and achieving normal levels of sleepiness and daily functioning. Sleep 30:711-719

16. Monasterio C, Vidal S, Duran J, Ferrer M, Carmona C, Barbe F, Mayos M, Gonzalez-Mangado N, Juncadella M, Navarro A, Barreira R, Capote F, Mayoralas LR, Peces-Barba G, Alonso J, Montserrat JM (2001) Effectiveness of continuous positive airway pressure in mild sleep apnea-hypopnea syndrome. Am J Respir Crit Care Med 164:939-943

17. Montserrat JM, Ferrer M, Hernandez $L$, Farre $R$, Vilagut G, Navajas D, Badia JR, Carrasco E, De Pablo J, Ballester E (2001) Effectiveness of CPAP treatment in daytime function in sleep apnea syndrome: a randomized controlled study with an optimized placebo. Am J Respir Crit Care Med 164:608-613

18. Marin JM, Carrizo SJ, Vicente E, Agusti AG (2005) Long-term cardiovascular outcomes in men with obstructive sleep apnoea-hypopnoea with or without treatment with continuous positive airway pressure: an observational study. Lancet 365:1046-1053

19. Campos-Rodriguez F, Pena-Grinan N, ReyesNunez N, De la Cruz-Moron I, Perez-Ronchel J, De la Vega-Gallardo F, Fernandez-Palacin A (2005) Mortality in obstructive sleep apnea-hypopnea patients treated with positive airway pressure. Chest 128:624-633

20. Anandam A, Patil M, Akinnusi $M$, Jaoude $P$, El-Solh AA (2013) Cardiovascular mortality in obstructive sleep apnoea treated with continuous positive airway pressure or oral appliance: an observational study. Respirology 18:1184-1190

21. McEvoy RD, Antic NA, Heeley E, Luo Y, Ou Q, Zhang X, Mediano O, Chen R, Drager LF, Liu Z, Chen G, Du B, McArdle N, Mukherjee S, Tripathi M, Billot L, Li Q, Lorenzi-Filho G, Barbe F, Redline S, Wang J, Arima H, Neal B, White DP, Grunstein RR, Zhong N, Anderson CS (2016) CPAP for prevention of cardiovascular events in obstructive sleep apnea. NEngl J Med 375:919-931

22. Fuhrman C, Fleury B, Nguyen XL, Delmas MC (2012) Symptoms of sleep apnea syndrome: high prevalence and underdiagnosis in the French population. Sleep Med 13:852-858

23. Deutsche Gesellschaft für Schlafforschung und Schlafmedizin (2017) S3-Leitlinie Nicht erholsamer Schlaf/Schlafstörungen - Kapitel "Schlafbezogene Atmungsstörungen". Somnologie 20(Suppl S2):S97-S180

24. Andersohn F, Walker J (2016) Characteristics and external validity of the German Health Risk Institute (HRI) database. Pharmacoepidemiol Drug Saf 25:106-109

25. von Elm E, Altman DG, Egger M, Pocock SJ, Gotzsche PC, Vandenbroucke JP (2008) The Strengthening the Reporting of Observational Studies in Epidemiology (STROBE) statement: guidelines for reporting observational studies. JClin Epidemiol 61:344-349
26. German Sleep Society (2014) List of accredited sleep laboratories. http://www.charite.de/dgsm/ dgsm/schlaflabore?language=english. Accessed 25 June 2014

27. Rosenbaum PR, Rubin DB (1985) Constructing a control group using multivariate matched sampling methods that incorporate the propensity score. Am Stat 39:33-38

28. Cochran WG, Rubin DB (1973) Controlling bias in observational studies: a review. Sankhya Ser A 35:417-446

29. Cai Q, Tan H, Singer J (2012) Impact of positive airway pressure among obstructive sleep apnea patients. Am J Manag Care 18:e225-e233

30. Jennum P, Kjellberg J (2011) Health, social and economical consequences of sleep-disordered breathing: a controlled national study. Thorax 66:560-566

31. de Batlle J, Bertran S, Turino C, Escarrabill J, Sanchez-de-la-Torre M, Woehrle H, Barbe F (2018) Mortality in patients treated with continuous positive airway pressure at the population level. Am J Respir Crit Care Med 197:1486-1488

32. Jennum P, Tonnesen P, Ibsen R, Kjellberg J (2017) Obstructive sleep apnea: effect of comorbidities and positive airway pressure on all-causemortality. Sleep Med 36:62-66

33. Woehrle H, Graml A, Weinreich G (2010) Adherence to CPAP therapy. Somnologie 14:135-139

34. Barbe F, Duran-Cantolla J, Capote F, de la Pena M, Chiner E, Masa JF, Gonzalez M, Marin JM, Garcia-Rio F, de Atauri JD, Teran J, Mayos M, Monasterio C, delCampoF, GomezS, dela TorreMS, Martinez M, Montserrat JM (2010) Long-term effect of continuous positive airway pressure in hypertensive patients with sleep apnea. Am J Respir Crit Care Med 181:718-726

35. Barbe F, Duran-Cantolla J, Sanchez-de-la-Torre M, Martinez-Alonso M, Carmona C, Barcelo A, ChinerE, Masa JF, Gonzalez M, Marin JM, Garcia-Rio F, Diaz de Atauri J, Teran J, Mayos M, de la Pena M, Monasterio C, del Campo F, Montserrat JM (2012) Effect of continuous positive airway pressure on the incidence of hypertension and cardiovascular events in nonsleepy patients with obstructive sleep apnea: a randomized controlled trial. JAMA 307:2161-2168

36. Duran-Cantolla J, Aizpuru F, Montserrat JM, Ballester E, Teran-Santos J, Aguirregomoscorta J, Gonzalez M, Lloberes P, Masa JF, De La Pena M, Carrizo S, Mayos M, Barbe F (2010) Continuous positive airway pressure as treatment for systemic hypertension in people with obstructive sleep apnoea: randomised controlled trial. BMJ 341:c5991

37. Lozano L, Tovar JL, Sampol G, Romero O, Jurado MJ Segarra A, Espinel E, Rios J, Untoria MD, Lloberes P (2010) Continuous positive airway pressure treatment in sleep apnea patients with resistant hypertension: a randomized, controlled trial. JHypertens 28:2161-2168

38. Montesi SB, Edwards BA, Malhotra A, Bakker JP (2012) The effect of continuous positive airway pressure treatment on blood pressure: a systematic review and meta-analysis of randomized controlled trials. JClin Sleep Med 8:587-596

39. Lyons OD, Floras JS, Logan AG, Beanlands R, Cantolla JD, Fitzpatrick M, Fleetham J, Kimoff RJ, Leung RS, Lorenzi Filho G, Mayer P, Mielniczuk L, Morrison DL, Ryan CM, Series F, Tomlinson GA, Woo A, Arzt M, Parthasarathy S, Redolfi S, Kasai T, Parati G, Delgado DH, Bradley TD (2017) Design of the effect of adaptive servo-ventilation on survival and cardiovascular hospital admissions in patients with heart failure and sleep apnoea: the ADVENTHF trial. Eur J Heart Fail 19:579-587 